Short Communication

\title{
Investigation of Electrochemical Property and Crystal Structure of Schiff Base Cobalt(III) Complex
}

\author{
Liyan You, Hui Jiang, Xianwu Dong and Chaohong $M a^{*}$ \\ Department of Chemistry, College of Arts and Science, Jilin Agricultural Science and Technology \\ University, No.77 Hanlin Rd, Jilin Economic and Technological Development Zone, Jilin, 132101, \\ P.R China \\ *Email: chaohongma_jast@qq.com
}

doi: $10.20964 / 2017.03 .38$

Received: 19 November 2016 / Accepted: 4 January 2017 / Published: 12 February 2017

\begin{abstract}
A Co(III) complex $(\mathrm{CoL}) \mathrm{Cl} \cdot 4 \mathrm{H}_{2} \mathrm{O}$ was successfully synthesized with a new Schiff base L. Structure analysis reveals that mononuclear cationic complex unit $(\mathrm{CoL})^{+}$with approximate octahedral geometry of central Co (III) ion existed in the as-prepared cobalt complex. The diameter of cobalt complex nanoparticles after the deposition on glass substrate was found to be around $63 \mathrm{~nm}$. In the cyclic voltammetry curves of cobalt(III) complex, two reversible redox waves ascribed to the consecutive redox processes of Co (III)/Co (II) and Co (II)/Co (I) pairs were found, suggeating the successful formation of $\mathrm{Co}^{\mathrm{III}}$ complex.
\end{abstract}

Keywords: Cobalt(III) complex; Schiff base; Electrochemical property; Crystal structure; FT-IR

\section{FULL TEXT}

(C) 2017 The Authors. Published by ESG (www.electrochemsci.org). This article is an open access article distributed under the terms and conditions of the Creative Commons Attribution license (http://creativecommons.org/licenses/by/4.0/). 